\title{
PALLIATIVE CARE AND BIOETHICS IN PEDIATRIC RHEUMATOLOGY
}

Aline Maria de Oliveira Rocha (Unifesp, SÃO PAULO, SP, Brasil), Annelyse de Araujo Pereira (Unifesp, Sao Paulo, SP, Brasil), Liana Soido Teixeira Silva (Unifesp, SÃO PAULO, SP, Brasil), Jade Dib Fernandez (Unifesp, São Paulo, SP, Brasil), Claudio Arnaldo Len (Unifesp, São Paulo, SP, Brasil), Maria Teresa Terreri (Unifeso, SAO PAULO, SP, Brasil)

\section{BACKGROUND}

Pediatric palliative care is intended to children with life-threatening conditions. In pediatric rheumatology we deal with many chronic diseases with no prospect of cure and depending on how the patient's evolution may lead to life threatening conditions, so discussing the issue becomes necessary with the assistant team.

\section{MATERIALS AND METHODS}

We seek to raise reflections and discussions on the subject from the knowledge already established by attending physicians of a specialized center of pediatric rheumatology. Thirteen physicians were approached among residents and assistants who answered a questionnaire about palliative care and bioethics in pediatrics based on experience during graduation, training and in clinical cases. The questionnaires were analyzed descriptively quantitative and qualitatively.

\section{RESULTS}

In terms of medical variety from residents to experienced assistants the ages of the interviewees ranged from 25 to 41 years and clinical experience time from 2.5 years to 16 years. The majority were nonpracticing Catholics (7/13) and coming from the Southeast region (5/13), followed by the South region (4/13). All reported having had little or no experience with palliative care despite the majority taking care of a terminal patient, especially as an assistant physician (11/13). Among those interviewed, 10 had some undergraduate or residency classes on some of the topics of palliative care, bioethics or communication of bad news, but considered that they received little information to manage patients who need palliative care. Most physicians (7/13) have no one to consult about palliative care, $8 / 13$ do not know the definition of the topic, but 11/13 answered they need to improve knowledge about the subject. When questioned about the understanding about palliative care the most discussed topics were about symptom control and pain and quality of life, and regarding the holistic approach saw the need to board the patient not only in their physical aspect but also in other dimensions, such as social, psychological and spiritual.

\section{CONCLUSION}

Although palliative care has initially been integrated into the care of oncological patients, it has been expanding to other areas of practice, such as Rheumatology, so that many patients can benefit from this approach. Therefore, we see the need to raise these reflections on patient management together with the assistant team. 